\title{
Correspondence
}

\section{Fibreoptic laryngoscopy after thyroid surgery}

\section{To the Editor:}

We would like to report the use of fibreoptic endoscopy as a method for evaluating vocal cord function following surgical procedures that could injure their innervation.

A 45-yr-old woman underwent resection of the thyroid isthmus and right thyroid lobectomy. Anaesthesia and surgery were uneventful but the surgeon requested that vocal cord function be evaluated laryngoscopically during extubation. Towards the end of surgery the patient was allowed to breathe spontaneously, and the anaesthesia was supplemented with $6 \mathrm{mg}$ of morphine. An Olympus LF1 endoscope (Olympus Medical Products, 8370 Dow Cr. Strongsville, $\mathrm{OH}$ 44136) was introduced nasally and directed toward the posterior fornix of the vocal cords. The vocal cords were examined with the endotracheal (ET) tube in place and bilateral movement was noted. Then, the cuff of the ET tube was deflated, and the tube was withdrawn past the cords. The area was inspected via the endoscope, and the vocal cords were seen to be in the normal position and moved with respiration. We then elected to remove the ET tube and finished the anaesthesia with mask ventilation. However, the ET could have been advanced into position after the examination. Postoperatively, there were no complications.

We feel that fibreoptic endoscopy is a simple, quick way to evaluate the vocal cords without subjecting the patient to an additional laryngoscopy with its potential risks and discomfort.

William B. Kelly MD

B. Gupta MD

Department of Anesthesiology

The Ohio State University Hospitals

Columbus, $\mathrm{OH} 43210$

\section{Bullard laryngoscopy for tracheal intubation of patients with cervical spine pathology}

To the Editor:

Direct laryngoscopy is the fastest and surest method of tracheal intubation. However, it necessitates anterior flexion of the lower cervical spine and atlanto-occipital extension in order to achieve axial alignment of mouth, pharynx and larynx, and bring the larynx within line-ofsight of the mouth and expose the vocal cords. Manipulations of the head and neck may not be permitted by a fixed cervical spine, and can be hazardous in patients with unstable cervical spine injury. ${ }^{1,2}$ Also, in-line axial traction or any other manoeuvre for head and neck stabilization may prevent complete alignment of the mouth and glottis.

Awake tracheal intubation has been suggested as an alternative technique for securing the airway in patients with cervical spine pathology. In the awake patient, blind nasotracheal intubation, visual fibreoptic laryngoscopy, as well as retrograde tracheal intubation may be attempted. ${ }^{1,2}$ However, these techniques have their difficulties if not practised frequently.

The Bullard laryngoscope (American ACMI, Stamford, Conn) has been designed as a combination of anatomically shaped rigid blade, with fibreoptic light source to aid direct visualization of the larynx. ${ }^{3-6}$ Anatomically, the blade is designed to match the anatomical airway rather than to align the airway to match the blade. These features facilitate visualization of the larynx in patients with cervical spine pathology, while maintaining the head and neck in the neutral position. Although visualization of the larynx is facilitated by Bullard laryngoscopy, passage of the tracheal tube along the side of the laryngoscope may be difficult whether it is achieved by the intubating forceps, ${ }^{3}$ or by a stylett formed to mimic the shape of the blade. ${ }^{5}$

The present report utilizes the "rail-roading" technique (i.e., introducing the tube over a bougie introducer) for facilitation of tracheal intubation by the Bullard laryngoscope. ${ }^{6}$ At first, a number 7FG ureteric catheter $70 \mathrm{~cm}$ long is used as an introducer. The pliable and atraumatic catheter is threaded into the passage of the intubating forceps prior to laryngoscopy. In order to use a larger bougie for facilitation of "rail-roading," a metal tube, 5 $\mathrm{mm}$ internal diameter and $14 \mathrm{~cm}$ long, was curved to conform to the curvature of the blade and was welded to its right side (Figure). Following visualization of the larynx, the bougie is threaded under vision into the trachea. The laryngoscope is then removed, leaving the bougie in situ. The tracheal tube is then threaded into the trachea over the bougie and the bougie removed.

The technique has been used successfully for orotracheal intubation in seven patients with cervical spine 


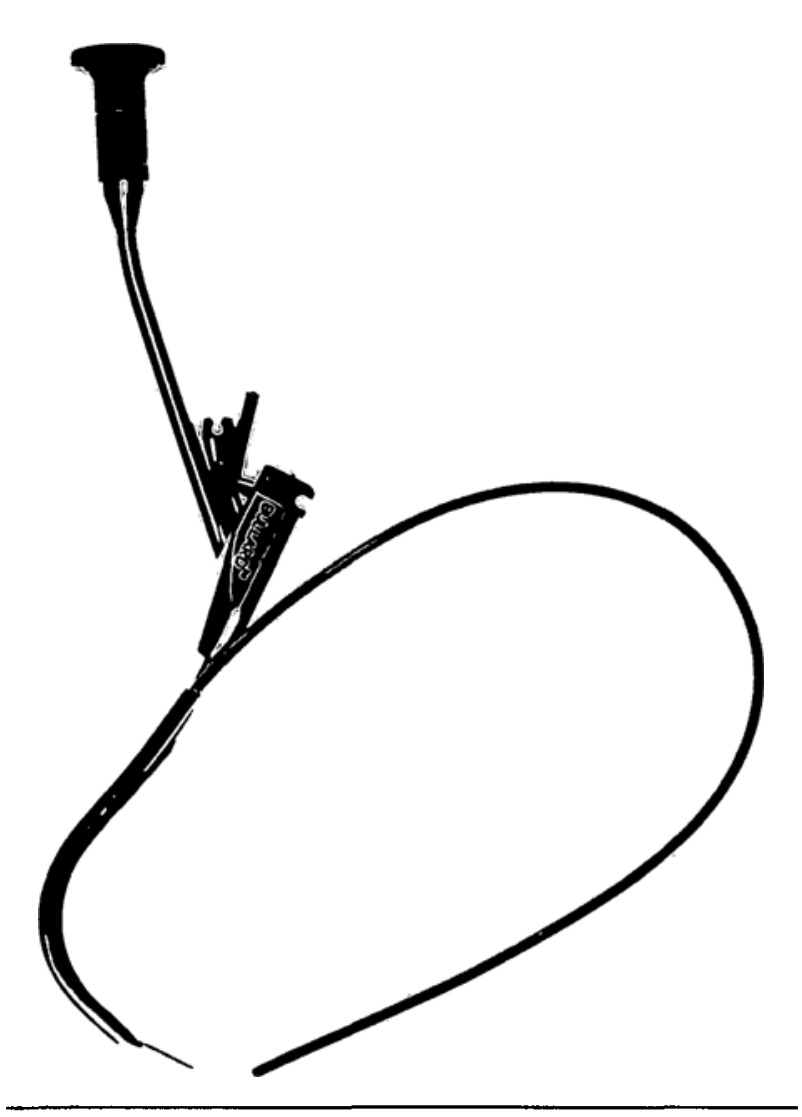

FIGURE The modified Bullard blade.

pathology. Awake tracheal intubation using topical anaesthesia was used in four cases, and thiopentonesuccinylcholine anaesthesia was used in three.

Anis Baraka MD

Musa Muallem MD

Abdel Nour Sibai MD

Faek Louis MD

Department of Anesthesiology

American University of Beirut

Beirut - Lebanon

\section{REFERENCES}

1 Suderman VS, Crosby ET, Lui A. Elective oral tracheal intubation in cervical spine-injured adults. Can J Anaesth 1991; 38: 785-9.

2 Hstings RH, Marks $J D$. Airway management for trauma patients with potential cervical spine injuries. Anesth Analg 1991; 73: 471-82.

3 Saunders PR, Giesecke $A H$. Clinical assessment of the adult Bullard laryngoscope blade. Can J Anaesth 1989; 36: S118-9.

4 Dyson A, Harris $J$, Bhatia $K$. Rapidity and accuracy of tracheal intubation in a mannequin: comparison of the fiberoptic with the Bullard laryngoscope. Br J Anaesth 1990; 65: 268-70.

5 Bjoraker DG. The Bullard intubating laryngoscopes. Anesthesiology Review 1990; 17: 64-70.

6 Baraka A, Muallem M, Sibai ANN. Facilitation of difficult tracheal intubation by the fiberoptic Bullard laryngoscope. Middle East J Anesthesiol 1991; 11: 73-7.

\section{Does propofol-nitrous oxide anaesthesia provide autonomic hyperreflexia $(A H)$ prophylaxis in susceptible patients?}

To the Editor:

I would like to report the case of an AH-susceptible patient who received a general anaesthetic with propofol and nitrous oxide. The patient was a 27 -yr-old, $60 \mathrm{~kg}$ male scheduled for incision and drainage of a perirectal abscess. During the preoperative visit it was determined that he had an incomplete spinal cord lesion at the $\mathrm{C}_{5-6}$ level. He had experienced episodes of $\mathrm{AH}$ on many occasions in the past, characterized by hypertension and headache and resulting from bladder overdistention. The patient received $10 \mathrm{mg}$ of oral diazepam as a premedication. In the operating room, fentanyl $150 \mu \mathrm{g}$, and d-tubocurarine $3 \mathrm{mg}$, were administered, the patient's lungs were denitrogenated with oxygen, general anaesthesia was induced with propofol $150 \mathrm{mg}\left(2.5 \mathrm{mg} \cdot \mathrm{kg}^{-1}\right)$ and muscle paralysis for tracheal intubation was obtained with succinylcholine $120 \mathrm{mg}$. Anaesthesia was maintained with $66 \%$ nitrous oxide in oxygen and a continuous variable-rate infusion of propofol, commencing at $200 \mu \mathrm{g} \cdot \mathrm{kg}^{-1} \cdot \mathrm{min}^{-1}$. The Figure provides the heart rate and blood pressure measurements recorded in the operating room (OR) and the recovery room (RR) with the elapsed time from induction of general anaesthesia provided along the $x$-axis. The details of the propofol infusion are also provided.

Initially the anaesthetic and operative procedure proceeded uneventfully. However, as the surgery was ending, the patient's BP was recorded at $190 \mathrm{mmHg}$ systolic and over $200 \mathrm{mmHg}$ shortly thereafter. His heart rate was below $50 \mathrm{bpm}$, he was diaphoretic and a diagnosis of AH was made. Two boluses of propofol $200 \mu \mathrm{g} \cdot \mathrm{kg}^{-1}$ were given and the infusion rate was increased. The systolic blood pressure decreased to $150 \mathrm{mmHg}$ as the dressing was applied. The propofol infusion was stopped and the lungs were ventilated with $100 \%$ oxygen. The patient awoke and the trachea was extubated. En route to the recovery room the patient complained of severe 